\title{
USING AUCTIONS TO ALLOCATE AND PRICE LONG-TERM CREDIT
}

\author{
J. Luis Guasch \\ Thomas Glaessner
}

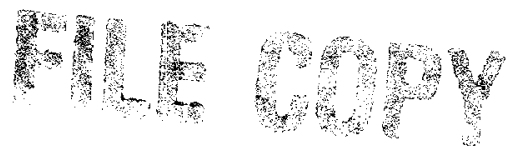

Most long-term credit in developing countries is allocated through negotiated agreements between government institutions and financial intermediaries or final borrowers, and often at administered rates. Yet many developing countries have no long-term credit market whose interest rates can be used as benchmarks for these loans. If credit is priced improperly, it will be allocated inefficiently and the development of capital markets may be stunted. In light of the generally disappointing experience with conventional methods of allocating development credit, some countries have introduced credit auctions as an alternative. Among the advantages are greater transparency and fairness, lower transaction costs, and increased competition and efficiency. Among the disadvantages are a greater vulnerability to collusion, which can lead to lower interest rates and revenue, and a tendency to attract the least desirable participants (adverse selection) and to lend for riskier projects (moral hazard), which can lead to lower repayment rates and a higher probability of default. All these factors can lead to inefficiency in the allocation of funds. This article suggests ways to lessen these negative effects and presents various elements of auction design that affect the efficiency of credit auctions and their suitability to specific circumstances. When properly designed, auctions can be used in a variety of environments to allocate development credit more efficiently than current methods do.

$\mathbf{M}$ ost developing countries seeking long-term financing in world capital markets either receive less credit than they want or are charged premium rates because of their high assessed financial and political risk. Consequently, they often turn to bilateral and multilateral lending

The World Bank Research Observer, vol. 8, no. 2 (July 1993), pp. 169-94

(c) 1993 The International Bank for Reconstruction and Development/THE WORLD BANK 


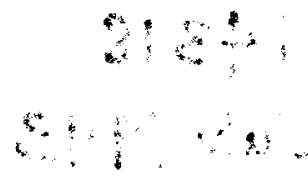

organizations for better terms. Sometimes the funds are used directly for government programs or projects, and sometimes they are channeled to the private commercial sector as long-term credit. Governments can usually get foreign credit on better terms than can private companies because of their access to official lenders and because they offer sovereign guarantees.

Whether the funds are channeled to the commercial sector through a government institution or a financial intermediary, pricing them at each stage in the lending chain is problematic. Many developing countries have no long-term credit market whose interest rates can be used as benchmarks. If credit is priced improperly, it will be allocated inefficiently, and capital markets may remain stunted. Furthermore, differences between the borrowing rates to government and any guesstimated interest rate to final borrowers are likely to be large enough to generate rents. And because relatively large sums are involved, the rents are often substantial. That means that the incentives for corruption and wasteful rent-seeking activities are large-and so are the corresponding welfare implications.

Pricing the funds at the opportunity cost of capital (market rates) at all stages of the lending chain minimizes these problems. The result is an efficient allocation of capital that provides the right signals for capital markets and allows the government to capture any rents. What, then, is the best mechanism for inducing pricing at market rates and for allocating credit efficiently?

The traditional approach has been to establish administrative arrangements for pricing and allocating credit. A government institution either lends the funds directly to final borrowers or operates as a second-tier financial institution, allocating and pricing funds through rules and bilateral negotiations with financial institutions that then lend the funds to final borrowers. The amounts and interest rates are usually negotiated between the lender and the borrower or are based on administered rules. That arrangement allows for significant discretion on the part of the lending government agency, and insofar as the rates are not market clearing, the excess demand presents the problem of how to ration the credit. Often the mechanisms for allocating and pricing credit are obscure, and prices do not reflect the opportunity costs of capital. And all too often this system has resulted in fraud and corruption, rent-seeking activities (with a large share of the rents captured by financial intermediaries and other influential groups), arbitrary allocations of credit, pricing distortions that impede the development of capital markets, and a worsening of income distribution.

To avoid such distortions and welfare losses, developing countries and international lending organizations alike began to explore alternative mechanisms for allocating long-term development credit. One alternative that has elicited considerable interest is auctioning development credit to financial institutions that meet certain minimum eligibility requirements. Bolivia and Chile, though quite different in the sophistication of their financial markets and the development of their economies, have both introduced credit auctioning in recent years. Honduras is scheduled to begin auctioning credit in 1993. Other coun- 
tries in Latin America and the Caribbean, including Argentina, Colombia, Ecuador, Jamaica, and Peru, are considering credit auctions. Mexico has recently implemented an auction that gives participants-financial institutions-the right to draw funds under certain specified conditions (credit-line auctioning).

This article looks at the rationale for credit auctions, various auction designs, and the tradeoffs involved, examining these issues within the framework of two overarching questions.

- What is the appropriate environment for auctioning development credit? What are the tradeoffs between allocating credit through auctions and allocating it through conventional bilateral negotiations with financial institutions?

- How should the auction be designed so as to allocate resources efficiently? Among the issues to be resolved: Should the objective of the auctions be to maximize expected revenue, to maximize efficiency, or to elicit high interest rates? How should participants be screened or certified? Should credit or credit lines be auctioned, and should a single product or multiple products be auctioned (products with fixed interest rates, with variable real interest rates, in various currencies and maturities)? What type of auction (oral or sealed bid) and pricing rules should be adopted? What should be done to avoid collusion or adverse selection? What information should be made public before and after the auction?

\section{Advantages and Disadvantages of Auctioning Credit}

Unlike sellers at auctions of goods, services, and securities, sellers at credit auctions do not receive the full value at the time of the transaction, and there is considerable uncertainty about the final outcome or realized net value. Risk is present because the credit is not fully collateralized and because the performance of subloans or projects is uncertain. Furthermore, inefficient financial markets may not provide accurate signals about the opportunity costs of capital or offer sufficient incentives to control for differences in information. To deal with these risks and imperfections, countries have relied on negotiated bilateral agreements to allocate credit. The great bulk of credit around the world is now allocated through bilateral negotiations that allow for assessing the risks of individual loans and borrowers and for credit rationing through quantity controls and individualized interest rates.

Relying on negotiated agreements is justified in industrial countries, where well-developed and efficient financial markets, market discipline, competition, and accountability provide the right incentives and environment to allocate credit efficiently. In developing countries, however, the use of negotiated agreements is more difficult to support because of weaker financial markets, lack of reference interest rates, less market discipline, lax accountability for financial and government institutions, and an often unstable macroeconomic en- 
vironment. And, indeed, performance, as measured by contracted interest rates, loan recovery rates, and degree of compliance with allocation targets, has been quite poor. These factors seem to argue for the need for a different institutional mechanism for credit allocations.

Why have neither governments nor markets responded with better mechanisms for allocating credit? And why have development banks often opposed proposals to auction development credit? One possible reason is that government agencies and financial institutions responsible for allocating development credit worry that auctions diminish their leverage and power to share rents with certain groups. What are the advantages and disadvantages of auctions?

\section{Advantages}

Credit auctions have at least five powerful advantages over conventional methods of disbursing credit.

- Transparency and fairness. The criteria for allocating credit are usually clear, and funds are distributed solely on the basis of bids. Individuals and institutions have little scope for favoritism or arbitrary behavior in allocating funds, so illicit deals between officials and credit seekers are difficult to arrange. Auctions also score high on fairness since all bidders have the same opportunity to bid on funds.

- Transaction costs. Conventional methods of disbursing credit have long been faulted for their numbingly detailed and time-consuming bureaucratic requirements that unduly prolong the time between application and approval and disbursement. The experiences of Bolivia and Chile show that auctions reduce the time and costs involved in allocating credit.

- Competition. Auctions give rise to more competitive behavior than do conventional bilateral negotiations, in which the possibilities for using political influence tend to attract rent-seeking behavior. Any advantages a bidder may have in an auction come from a greater efficiency in processing loans or assessing risks, from a greater willingness to bear risk, or from legal restrictions that bear on the costs of raising funds elsewhere. In countries where there is no obvious reference interest rate for long-term funds, credit is more likely to be allocated at interest rates that reflect the opportunity costs of funds through auctions, where borrowers set the rate with their bids, than through conventional lending mechanisms, where the lender usually determines the rate. Because the borrower has better information than the lender about the opportunity costs of capital, auctions can allocate funds more efficiently.

- Rent-seeking activities. Auctions virtually eliminate opportunities for rentseeking. Clear rules and the open and competitive nature of auctions leave little opportunity for wasteful rent-seeking activities, particularly if the problem of collusion is properly addressed. 
- Price discovery. Auctions of long-term development credit are particularly appropriate in countries without an equivalent financial market instrument. Long-term credit is often intended to facilitate and promote the development of a securities market, and the prices elicited at auctions can serve as references and signals for enterprises that are considering the issuance of long-term debt. ${ }^{1}$

\section{Disadvantages}

Auctions have several disadvantages. Collusion among financial institutions, difficult under conventional lending practices, is a real threat in credit auctions. In many countries the small number of banking or financial institutions-with a history of collaboration among them-and tight oligopolistic markets suggest that collusive or coordinated activities are likely to be considered.

Auctions exacerbate some problems that arise in conventional lending. One is adverse selection, or the tendency to attract the least desirable participants, in this case those with the highest risks. Auctions are relatively more attractive to institutions with high propensities to take risks, so those institutions will end up with a larger-than-desirable proportion of funds, increasing the probability of defaults. There are systematic reasons for supposing that institutions willing to offer the highest bids for funds present a greater-than-average credit risk. Riskier banks have higher alternative costs of funds than less risky ones, so to place new debt (bonds), or to attract new deposits, for example, riskier banks must offer higher interest rates. Thus it is consistent for high-risk institutions to bid higher rates than less risky ones. In that sense, auctions bias the allocation of funds in favor of riskier institutions. In credit auctions, then, higher rates need not reflect greater efficiency or higher expected revenue to the lender, since the probability of default can also be higher.

Another problem auctions share with conventional lending is moral hazard, that is, the inability of the lender to control how the borrower uses the funds. The higher the interest rates bid in an auction, the more likely the intermediate lender will feel compelled to lend for riskier projects or investments at higher interest rates, thereby increasing the probability of default. The problem looms larger in credit auctions than under conventional, negotiated agreements because in auctions there are generally no restrictions on interest rates or on the total amount of funds that can be awarded to an institution. Conventional lending practices rely on quantity rationing and the use of more extensive and complex contractual terms to protect against this problem.

Collusion leads to lower revenue and interest rates, while adverse selection and moral hazard lead to lower repayment rates (higher probability of default). And all of them generate inefficiencies in the allocation of credit. There are ways to lessen these effects, however, through the design of the auction mechanism or through complementary measures. When properly designed, auctions 
can be used in a variety of environments to allocate development credit more efficiently than current methods do.

\section{When to Consider Credit Auctions}

Credit auctions are not appropriate in all environments. For one thing, development credit auctions should be part of an overall program of financial sector reform. Beyond that, credit auctions may be an appropriate option when the following conditions exist.

- Current mechanisms do not allocate credit fairly and efficiently, and the rents are not fully captured by the intended beneficiaries. There should be substantial evidence of arbitrariness, favoritism, or corruption in the existing scheme; large discrepancies between onlending rates to first-tier institutions (that is, lenders to final users) and final borrowers relative to some quasi-market rates or the opportunity cost of capital; and unsatisfactory repayment rates.

- There is no reasonable proxy reference interest rate for long-term credit to use as a benchmark in negotiated agreements. In countries where macroeconomic and political volatility are high, uncertainty about the value of longterm credit is usually so great that no market exists for such instruments. In many developing countries, the maximum term for loans is one year. When there is no obvious reference rate for long-term credit, auctions will probably come closer to reaching a true assessment of the value of longterm credit than would government agencies trying to set a rate through negotiated agreements.

- There is evidence that competition exists or can be induced in the banking and financial sector. The likelihood of collusion falls as the number of participants rises, but most of the gains from competition are captured when there are at least three to five participants. After that, the additional reduction in the potential for collusion that comes with each additional participant is fairly small.

- State-owned banks do not dominate the banking sector. Auctions of credit by the government to state-owned banks could result in more distress bidding (uncorrelated with and often above valuations) and in prices that do not reflect opportunity costs. The lack of market and financial discipline in those institutions is likely to undermine the benefits that auctions can provide. And because the government is both buyer and seller and so could manipulate the outcome, the auction loses credibility.

- Supervisory agencies have demonstrated the competence and administrative capacity to monitor and assess the credit risk of potential participants. Unless adequate supervisory infrastructure is in place, problems of adverse selection and moral hazard can be exacerbated, diminishing the effectiveness and efficiency of development credit auctions. The absence of this critical 
institutional infrastructure would, of course, present problems for any mechanisms for allocating development credit, not just auctions.

Two other special circumstances merit mention. Governments should not use auctions to create a market for types of lending products that could develop on their own within a country's existing capital market. In countries such as Chile that have a well-developed financial system with rapidly developing capital markets and nonbank financial institutions, auctions need to be designed with special care to complement rather than retard the development of these markets. For example, when the Chile Development Bank auctions off multiple, customized products including fixed real rate loans, other lenders have less incentive to offer those types of assets, which may retard the development of domestic swap-market-like instruments for transforming floating real rate loans to fixed real rate instruments.

Controlled interest rates are another special circumstance. Although some of the benefits of auctions may be lessened when interest rates are controlled, auctions under those conditions enable the government to capture rents that would otherwise go to financial intermediaries. Under administered interest rates one rate is set for the final borrower and another for the financial intermediary, with the spread between the rates large enough to cover the costs of lending and with both rates lower than the "market" rates. On paper all parties comply with the fixed rates. But in practice some of the rents (the difference between the administered rate and the "market" rate) intended for the final user actually go to the financial intermediary, as a result of under-the-table negotiations. With an auction mechanism, only the rate to the final user is set. Financial intermediaries, in deciding what rate to bid, start from the fact that the funds will have to be lent at the controlled rate. If there are no under-thetable arrangements, the bids will reflect efficiency in intermediation only. If there are under-the-table agreements, competition for funds will push bid rates up, allowing the government to capture some of the rents that would have gone to intermediaries. ${ }^{2}$ Implementing auctions under these circumstances might create greater pressure to liberalize interest rates.

\section{Design Issues}

Credit auctions can take many different forms. Among the design issues to be considered are who should be allowed to participate, what products should be auctioned, what bidding and pricing rules should apply, and what information should be made available to participants.

\section{Who Should Participate?}

The structure of the banking system and its mode of ownership are the two primary considerations for establishing participation criteria. The important 
aspects of structure are the degree of competition and the performance history of the sector.

Where most of the financial institutions are privately owned and the sector operates competitively, only private institutions should be allowed to participate in auctions. In countries with a developed leasing market or other nonbank financial sector, private companies engaged in those activities could join banks as participants. Since leasing firms specialize in long-term lending, allowing them to participate would reduce financial intermediation costs and increase efficiency, as Chile's experience shows (Guasch and Glaessner 1992). The participation of other types of institutions is particularly beneficial when competition in the banking sector is weak. With a larger pool of participants and greater heterogeneity among them, the opportunities for collusive arrangements shrink.

Where there is a mixture of state and private ownership in the financial sector, credit auctions can still be an effective mechanism for disbursing credit. Only privately owned institutions should be allowed to participate directly, but state-owned institutions could be allowed an indirect role through noncompetitive bidding: state-owned institutions that meet all eligibility requirementsexcept, of course, private ownership-could have the option of obtaining funds at the average interest rate prevailing at the auction. This is usually done by setting aside funds. The quantity depends on the demand by state institutions and total funds available. The auction committee makes the decision, subject to publicly known guidelines.

Where most banking and financial institutions are state-owned, auctions are not an appropriate mechanism. Bid rates are likely to be meaningless in the absence of market and financial discipline. The opportunities for manipulating interest rates would cast doubt on the integrity of the process as well. Negotiated rates, based on whatever "market" indexes are available, would be preferable under those circumstances.

Once eligibility has been broadly established, finer screening will be needed to keep out high-risk institutions. An independent risk-rating agency should be used to determine which institutions should be excluded. The best control over adverse selection is to establish a clear set of certification criteria, based on external rating when available. It is also important to establish limits on the amount that any one institution can borrow, particularly the weaker ones, with the amount being adjustable over time according to the institution's performance. This feature introduces discretion to the auctioning committee, but no more than in negotiated bilateral agreements.

\section{What Products Should Be Auctioned?}

Decisions need to be made about whether to auction credit or access to credit (credit lines), whether rates should be fixed or variable, and whether a 
variety of maturities and currencies should be offered. When credit is auctioned, bidders submit a two-part bid listing quantity and interest rate desired; successful bidders receive the desired quantity shortly after the auction. When access to credit (credit lines) is auctioned, the auctioneer selects an interest rate, and bidders submit a quantity bid and a nonrefundable fee for the right of access to that amount of credit at that interest rate over a specified period selected by the auctioneer. Bids are ranked from highest to lowest according to the fee per quantity bid. Any funds not drawn down by the end of the specified period revert to the auctioneer.

When credit is auctioned, bidders prepare projects or loans, usually contracted on a contingency basis, before the auction and are ready to relend the funds immediately. Credit lines allow more time for the use of funds and do not require awarded funds to be matched with loans or projects at the time of the auction. Matching is required only when the awarded credit line is disbursed.

The two alternatives are likely to elicit similar effective interest rates at the auction, but credit lines entail greater risk than credit, resulting in lower expected returns. Two opposing forces are at play here. On the one hand, with credit lines participants are bidding before contracts with final borrowers are in place, so the rates at which they will be able to place the funds are somewhat uncertain. If risk-averse behavior predominates, on average, lower rates will be bid for credit lines than for credit. On the other hand, credit lines are more attractive to participants than credit because of their loan-smoothing property. Credit lines allow for projects to be processed as they arrive, without undue delays or uncertainty about funding or about the cost of funds to the sublenders. Because credit is more constrained than credit lines, institutions should be willing to pay a premium for credit lines over credit. These two forces may cancel each other out, resulting in similar bids for credit and credit lines.

The greater risk in auctioning credit lines rather than credit arises because, as institutions lock in funds at the auction, competition among them for projects and loans is likely to increase, particularly as the expiration date for the credit line nears. The fact that the option right to the credit line is nonrefundable - a sunk cost—adds further pressure to on-lend the funds. The likely effect of these two factors is to reduce spreads or profits, perhaps below prudential levels, and to increase the temptation to accept riskier projects or loans in order to lock in some of the expected gains. Thus, the credit line alternative is likely to increase the severity of the moral hazard problem.

It is clear that there are tradeoffs between credit and credit lines. The net effect has to be determined individually for each environment. In general, however, the effective difference between the two alternatives is unlikely to be very large. If degree of risk and ease of administration are key concerns, auctioning credit is a slightly better choice than auctioning credit lines.

A second set of issues concerns the number and type of products to be offered. Products are differentiated by currency, term, and presence or absence 
of indexing. For reasons of efficiency, transparency, and operational simplicity, auctions should start off with a single, fixed-rate product (but indexed for inflation), denominated in domestic currency, with a four- to six-year maturity and open to use in any sector.

Because the marginal returns vary on each type of credit product, offering multiple products requires establishing criteria for comparing rates and allocating funds efficiently across products. This is not a trivial problem. It involves assessing premiums on instruments with a variety of terms, taking into account interest rate volatility and exchange rate risks. Governments have no comparative advantage in making such assessments, nor should they play the role of market maker-the private sector is better suited to the task. Moreover, any criteria developed by a government agency for comparing rates across products would likely be indicative at best. Significant discretion would be left to those in charge of the award process, endangering the openness and credibility of the process. Indeed, there is evidence of just such a loss of transparency in the development credit auctions in Bolivia and Chile. Because auctions are held regularly, some flexibility should be built into the process of product selection. If the preferences of credit users change, the product offered should change in response. But only one product should be offered at a time, at least at first.

Fixed-rate (but indexed for inflation), long-term credit is the scarcest form of credit in developing countries, yet it appears to be the most desired; in quantities demanded and bid rates submitted, it is clearly the winner in credit auctions in Chile. High political and macroeconomic risk-and the unwillingness of borrowers to pay the risk premium-explains its absence in most developing countries. Development credit can thus make its largest contribution and produce the most value added in the form of long-term, fixed-rate credit. (Note that providing and auctioning fixed-rate, long-term credit where no market previously existed implies a de facto subsidy.) For efficiency reasons, credit should go wherever it can claim the highest expected return, regardless of sector-unless, of course, high rates of return reflect monopoly control or other distortions in a particular sector.

Also for efficiency reasons, the credit should be denominated in a country's own currency rather than in a foreign currency. Because the original loan or credit line is denominated in a foreign currency and the final credit is generally expressed in the local currency (unless the economy is dollarized), there is an exchange rate risk. The issue is who should bear the risk. The government is arguably the least risk-averse participant and to a large extent controls exchange rate policy, so economic efficiency argues for the government or central bank to bear the risk-particularly where there are no organized forward markets for foreign exchange. In dollarized economies, however, where there are competitive domestic interest rates for borrowing in dollars, auctioned credit should be denominated in dollars. 


\section{What Bidding and Pricing Rules Should Apply?}

Most of the literature on auctions deals with single-object sales-that is, with indivisible products that can go to only one bidder-and one-time auctions, primarily for reasons of analytic tractability. The literature also generally assumes no collusion by participants. Thus, although the literature provides a base of reference, most studies are of limited value for the type of auctions proposed here because none of these conditions holds for long-term credit auctions. First, credit-the "object" of the auction-is fully divisible and can be awarded to several bidders. Second, credit auctions are repetitive. Repetition, particularly for a homogeneous good, generates an informational and strategic component related to the bids and valuations of other bidders, leading to significantly different results than with single-object auctions. And third, as mentioned, participants have significant incentives to engage in collusive practices. The analysis here concentrates on the few studies of multiple-object, repeated auctions that account for the possibility of collusion.

BIDDERS' VALUATIONS. Credit auctions typically involve the allocation of many individual blocks of credit in a process repeated through time. If one bidder has a high valuation for the credit being auctioned, others are likely to have a high valuation as well. In the vernacular of the auction literature, credit auctions are repeated multiple-object auctions in which bidders' valuations are affiliated. Affiliated valuations imply that although bidders may have different assessments about how much credit is worth to them-say, because of access to different information or because of different costs-their valuations depend on each other's. That is precisely the case for credit: as a bidder's estimate of value rises, the bidder expects others' estimates to rise as well.

Bidders' valuations largely reflect the rates at which they believe they can sublend, risk factors included. Knowledge about that information affects other bidders' valuations (if not for the present, since contracts may have been locked in, then certainly for the future). Uncertainty about valuations is slightly higher with credit lines than with credit. With credit, contracts for subloans are usually locked in before the auction, so each bidder has complete certainty about the value of credit. With credit lines, contracts have not yet been solicited or negotiated, and that generates some uncertainty about the value of credit to the bidder. But in both cases the bidders' valuations are affiliated.

Although sublending rates might generate little uncertainty or discrepancy among bidders, the risk with respect to the net value of credit or expected returns is substantial. Considering that the macroeconomic environment is often unstable and that subloans are extended for long terms, repayment rates are bound to be difficult to forecast with much accuracy. Differences in bidders' valuations are likely to come from differences in information and in alternative costs of funds, processing costs, and risk assessment of subloans. Nonuniform legal restrictions may account for some differences in valuation as well, say, if 
some institutions are not allowed to accept deposits or have no access to rediscount windows. And some of the differences may stem from differences among institutions; some may be more efficient in processing loans or have better skills in assessing risks or different attitudes toward risk. All these factors will generate some dispersion in bidders' valuations or reservation interest rates.

SELLERS' OBJECTIVES. Auction theory assumes that the seller's objective is to maximize expected revenue and that efficiency, in an auction context, means allocating the products to be auctioned to the bidders with highest valuations. Efficiency is an issue because rankings of submitted bids and rankings of valuations need not coincide in an auction since participants' bids do not necessarily correspond to their valuations. Auction designs are thus assessed according to how well different types of auctions score in these objectives.

With credit auctions, the concerns are even broader, however. The objectives of credit auctions are to induce credit rediscounting rates that reflect the opportunity cost of capital, to avoid arbitrary or noneconomic biases in allocating credit, and to improve recovery rates. The government, unlike a private institution, should be concerned with efficiency rather than profit maximization: the objective of the auction should not be to elicit the highest interest rates but rather to maximize expected returns, since expected returns take into account the risk of default. With multiple winners, the issue of efficiency is usually moot, because any type of auction will likely be efficient. Even though the ranking of the winning bids may not coincide with the ranking of valuations, the rankings are likely to coincide in the aggregate-for example, the highest five bids will likely correspond to the highest five valuations. And even when they do not, the loss of efficiency is likely to be small. Thus the maximization of expected returns or revenue is a legitimate and proper objective for guiding auction design.

TYPES OF AUCTIONS. In the theoretical literature, the optimal auction design for a revenue-maximizing seller involves selecting a probability of winning and an expected-payment rule, subject to a set of feasibility conditions. For example, a sealed-bid auction that specifies that the highest bidder will win (probability of winning) and will pay the amount of the second highest bid (expectedpayment rule) is optimal in certain restrictive environments. But implementing credit auctions in far less stylized environments gives rise to a host of practical questions about tradeoffs between oral and sealed bids, uniform and discriminatory price rules, and sequential and simultaneous auctions. Each has its advantages and drawbacks.

The following auction options highlight some of these dimensions. The options are not equivalent in many ways, and tradeoffs among them need to be evaluated for the particular circumstances to which they will apply. 
- Discriminatory price auction. In discriminatory price auctions, bidders submit sealed bids, and funds are distributed to the highest bidders down to the level of the bid at which funds are exhausted or the floor price-the seller's reservation price-is reached. Winning bidders pay the price they submitted, that is, their implicit or explicit interest rate. This procedure is used in the sale of U.S. Treasury bills. A discriminatory price auction is called a first-price auction if there is a single item to be auctioned.

- Uniform price auction. Uniform price auctions work in the same way as discriminatory price auctions except that all winning bidders pay the same implicit or explicit interest rate- usually the rate just below the cutoff bid or below the lowest accepted bid, whichever is greater. This procedure is used in the sale of long-term U.S. Treasury bonds and has been used by the Mexican government in placing its debt securities. ${ }^{3}$ A uniform price auction is known as a second-price auction if there is a single item to be auctioned.

- Priority-level price auction. Priority-level pricing may be used when there are several distinct types of bidders, each with a significantly different valuation of the object being auctioned. Different alternative costs of funds or risk classifications among classes of financial institutions could account for such differences in a credit auction. The primary purpose of a prioritylevel price auction is to induce "desirable" classes of bidders to bid or to bid more aggressively than they otherwise would and to handicap the classes on economic grounds. For example, for higher-risk classes, two percentage points, say, would be subtracted from their bids, and their bids would then be ranked along with the others. Of course, if awarded funds, the higher-risk bidders would pay their submitted bid. Thus, bids from those in the lower-valuation groups are favorably handicapped relative to those from higher-valuation groups through the use of assigned priority levels.

- English auction. English auctions, in our context, use an interest rate clock, and bids are monitored electronically. Bidders must be present at the auction. As the auction begins, the interest rate clock is set at a low level, and the rate rises continuously throughout the auction. Bidders who wish to remain active keep their buttons depressed as the rate rises, releasing the button to indicate a bid. The interest rate at which a bidder releases the button is recorded, and when all bidders but one have released their buttons, the funds are allocated from that bidder down until the funds are exhausted or the seller's floor price is reached. Each bidder pays the interest rate shown on the clock at the time the button was released by the preceding bidder. The U.S. Forest Service has used English auctions to sell contracts for harvesting timber.

- Dutch auction. Dutch auctions also use an interest rate clock, but the clock runs backward from a very high initial rate. Bidders place a bid for a certain quantity of credit by pressing a button that stops the interest rate 
clock at the rate they wish to bid. That quantity is assigned to the bidder, and the interest rate clock then resumes its descent until another bidder stops it. The process ends when all available funds have been allocated or the clock reaches the floor interest rate. Dutch auctions are used in several European countries for wholesale sales of fruits, vegetables, and flowers. ${ }^{4}$

The auctions described above are of the simultaneous form, with all funds allocated in a single round. In sequential auctions, funds are allocated one winner per round, sequentially through several distinct rounds of auctions, until the funds are exhausted. For example, in a sequential, discriminatory price auction, the bidder who submits the highest interest rate bid is allocated the requested funds in each round. The remaining bidders then submit new sealed bids, and new rounds are conducted until all funds are allocated or the highest bid is below the floor price. The auctioneer can choose whether to reveal the terms of the winning bid to the remaining bidders before the next round. The auctions are then qualified as being with or without price and quantity announcements (discussed below).

Which of these auction types is best for the kind of long-term development credit auction being considered here, with maximization of expected returns as its objective? The appendix presents some findings from a comparison of various auction types. But several caveats are in order. Theoretical studies can provide only partial rankings, with qualitative but not quantitative results on what forms of auctions are better than others. These studies also presume or indicate that differences in expected returns are likely to be small in percentage terms (of second-order effect). What scarce evidence there is for this presumption comes from imperfect comparisons of real auctions and from experimental data (Hendricks and Porter 1988; Hendricks, Porter, and Boudreau 1987; Plott 1982; Smith 1982; and Hansen 1985, 1986).

Complexity and transaction costs must also be considered. Oral auctions are more complex and have higher transaction costs than sealed-bid auctions, particularly for the bidders; the same is true of sequential auctions compared with simultaneous ones. In sequential auctions bidders must reassess their strategies and bids for the next round in light of the information and outcomes at the end of each round. That can be a complex task, requiring intellectual dexterity and sophisticated computational skills. The analysis presented in the appendix assumes that bidders fully understand the procedures and act in an optimally rational way. What still needs to be considered is how the level of complexity of an auction affects bidders' ability to submit strategically optimal bids. ${ }^{5}$

Perhaps the largest shortcoming in auction theory for ranking performance in frameworks similar to ours is the assumption that collusion among bidders is not a factor. Without collusion, differences in expected returns among various types of auctions are small, but with collusion the differences can be substantial. Priority should thus be given to auction designs that are the least vulnerable to collusive arrangements. 
Some types of auctions tend to facilitate collusion more than others. What little is known about the issue has come largely from studies of single-object auctions (recall that credit is not a single object). The literature suggests that second-price and English auctions are vulnerable to coalitions of any size. By contrast, it is conjectured that only all-inclusive coalitions are viable in firstprice auctions (discriminatory price auctions, Dutch auctions, and sealed-bid auctions) and that these coalitions appear to be inherently unstable (Graham and Marshall 1987; Graham, Marshall, and Richard 1990). ${ }^{6}$

The ability of bidders to subcontract among themselves appears to be important, since it provides a means of sharing the gains of collusion. Credit auctions seem to provide the right conditions for collusion. The bidders are commercial banks, whose managers are likely to know each other well and to participate in many joint ventures. Although the subcontracting of auction funds is technically forbidden, because funds are tied to projects, the inherent fungibility of money makes subcontracting a relatively simple matter. Interbank loans-subcontracting in the banking industry, if you will-are legal and common. If bidding patterns are suspect, the interbank loans or joint projects of the institutions involved should be monitored and audited.

So what is the best choice? If collusion is ignored, sequential English auctions appear to generate the largest expected revenue (see appendix). But English auctions are notorious for their susceptibility to collusive practices (Graham and Marshall 1987). Furthermore, computing optimal strategies is not a simple matter, particularly for sequential auctions. Thus, there is no assurance that the equilibrium or optimal strategies will be used, which could vitiate the results predicted from the theory. When all this is taken into account, the best (constrained) design is a sealed-bid, discriminatory price auction. Such auctions are the least vulnerable to collusion, their transaction costs are low, they require relatively little computational sophistication from bidders, and the marginal revenue loss compared to the first-best solution-sequential English auctions-is quite small. Furthermore, although the English auction seems to lead to higher revenue for the seller, empirical evidence indicates that in many settings both types of auction generate similar expected revenues. ${ }^{7}$

Priority-level auctions are an alternative worth exploring when the possibility of collusion among traditional banks is high or when several types of eligible financial institutions with different alternative costs of funds or risk classifications are participating. Two major benefits accrue from bringing together two different groups of bidders at a common auction: increasing the number of bidders increases expected returns, and heterogeneity of participants makes collusion more difficult (Harris and Raviv 1981). The main drawback of a system of handicapping is that it can open a Pandora's box of opportunistic favoritism and rent-seeking during the handicapping process that could jeopardize the transparency and legitimacy of the auction mechanism.

An even more basic question is why favor any group in an auction? And if a group is to be favored, should it be done through prices or quantities? There 
are several reasons to favor one group over another. ${ }^{8}$ When risk differentials between the groups are significant, it is efficient to discriminate because loans at identical interest rates will generate different expected returns. If the two groups differ significantly in their valuation of credit, there might not be enough institutions with the higher valuations to induce competition; then favoring the bids of the group with the lower valuations could increase competition. Similarly, when collusive practices among the higher-valuation group are suspected, favoring the other group can be an effective way to encourage its participation, making collusion more difficult.

And sometimes priority auctions are desirable when the use of funds by each group differs significantly and having funds available for both uses is considered important. Chile decided it was important to allocate funds to both banks and leasing companies and so set up separate auctions for the two kinds of institutions. In Chile holding separate auctions for banks and leasing companies favors banks over leasing companies, because banks are usually awarded funds at bids lower than the losing bids by the leasing companies. In that sense, prices are used to favor the banks. An alternative would be to impose quantity constraints on the amounts leasing companies can borrow.

OTHER BIDDING AND PRICING ISSUES. Another choice in auction design is between multiple and single bids. Here the answer is clear-cut: each bidder should be allowed to submit as many bids as desired for each product auctioned. The advantages of allowing multiple bids are substantial and very likely outweigh any additional transaction costs. Multiple bids provide for portfolio diversification, as a larger number of small-quantity bids are elicited at high interest rates. Allowing multiple bids should also increase efficiency. When only single bids are allowed, participants are forced to combine their projects or loans into one average bid rather than a collection of marginal ones reflecting different expected rates of return on projects. Forcing the use of average rather than marginal bids induces distortions and inefficient allocation of funds: some projects that should have been funded on the basis of expected rate of return are not, and some that should not have been, are. Finally, permitting multiple bids makes collusion more difficult.

Frequency also needs to be considered. Spreading available funds-which are usually provided through a loan from a bilateral or multilateral institution-over a number of auctions held throughout the year offers several advantages over a single auction. Collusive arrangements have to be more complex, which makes them easier to detect and more difficult to coordinate and sustain. ${ }^{9}$ Theories of risk and myopic behavior also suggest that auctioning small quantities of funds over time rather than a large quantity all at once might elicit more aggressive competitive behavior from bidders, despite their knowledge that other auctions will be held some time in the near future. Estimates of excess demand around relevant interest rates should aid in determining whether that will be the case in specific circumstances. Also, increasing the number of 
auctions approximates sequential auctioning, which, as argued above, should boost expected returns. Lending efficiency may also improve because subborrowers' projects are likely to be spread over the year as well. Finally, having a larger number of auctions allows for rolling assessments of results and finetuning of design to correct for observed or suspected problems, particularly collusion. Any increase in transaction costs because of the larger number of auctions should be more than compensated for by gains in efficiency.

Entrance fees are another issue. Levying a nonrefundable entrance or application fee can lower administrative costs and improve the efficiency of auctions through participant self-selection. Screening applicants to ensure that they meet established legal, financial, and risk criteria consumes the limited administrative resources. Entrance fees can cover and internalize the costs of evaluating the financial soundness of institutions applying for the auction. If the fees are high enough, they will also serve as a self-selection device, dissuading financially unfit institutions from applying. That increases efficiency, because only institutions likely to conform to the eligibility criteria will apply.

\section{What Information Should Be Disclosed to Participants?}

Before an auction bidders face four sources of uncertainty: the valuations and bids of other participants, the floor price (if any), the volume of funds to be auctioned, and the quantities demanded by other bidders. The last twouncertain supply and uncertain demand-while appearing to be strategically equivalent, are not. Collusion could provide information on quantity demanded but not on quantity supplied. The disbursing agency has control over two of the sources of uncertainty: the floor price and the quantity to be auctioned. Should that information be disclosed to participants?

Auction theory argues for revealing information that affects bidders' valuations and thus their bidding (quality information). Because bidders know that the seller knows the total amount to be auctioned and the floor price, bidders assume answers that are the least favorable to the seller when the seller fails to reveal the information. Bidders adjust their bids accordingly. Because that would reduce expected revenue, there appears to be nothing to lose and much to gain from revealing the information.

The picture is not quite as simple as that, however. That argument has been shown to be correct for risk-neutral bidders, but not necessarily for risk-averse bidders. When bidders shun risk, uncertainty about the quantity of funds to be awarded will, on average, raise bid rates. ${ }^{10}$ Similarly, the argument may be valid for single auctions but not for repeated auctions, where there is the possibility of a credible commitment by the seller to withhold information. That is, information that would not be credible to withhold in a single auction can be credibly withheld in a repeated auction because of the learning by buyers at the end of each auction. 
The possibility of collusion also weakens the argument for sharing information with bidders. Uncertainty about the amounts to be awarded at the auction or the amounts that were awarded at a previous round makes coordination more difficult and is likely to induce more aggressive bidding. And uncertainty about the floor price means that a bidders' coalition does not know by how much it can reduce the bid before falling below the seller's floor price. Announcing the floor price in advance provides the coalition with a convenient starting point for coordinating its behavior. Keeping the floor price secret has generally been shown to increase expected revenue. Bolivia's auctions underscore the point. In the ten or fifteen auctions it held between September 1990 and January 1992, more than 90 percent of the bids were at the announced floor price. ${ }^{11}$ Also, to facilitate cheating against collusive agreements, the specifics of the winning bids should not be disclosed. In summary, neither the floor price nor the amount of funds to be auctioned should be made public.

A short aside on floor prices. We have argued that auctions are most useful in environments where there are no equivalent reference rates for pricing longterm funds. Yet we have advised the use of a floor price based on "market" rates, an apparent contradiction. If collusion were not a problem, competition and repetition would render the floor price issue moot. The main purpose of the floor price is to limit the loss of rents to the government as a result of collusive arrangements. But how should the floor price be set? As a start, market rates for shorter-term instruments (30- to 365 -day bank deposits, prime rates, government cost-of-funds rates, and 90-day-or-more treasury bills or bonds) can be used to establish an initial floor price. Since auction rates are indexed for inflation, long-term funds should not be awarded at rates lower than those.

Even if most bids fall below the selected levels, the government should stick to the floor price. When there is no history of long-term credit rates, participants will test the waters at the beginning by bidding low rates. Chile's auctions illustrate that well. Most bids at the first auctions were below the floor price, which was a weighted average of the 90- to 365-day bank deposit rates. By the third auction, no bids were below that average, and price discovery was well under way. In Bolivia the banking sector boycotted the first auction, expecting its challenge of the new regime to affect floor rates. Eventually, the banks came to terms with the auction arrangement, recognizing the government's determination to stick to the new rules and floor price.

\section{Experience in Bolivia and Chile}

What has experience with long-term credit auctions shown? Bolivia and Chile have been holding such auctions for private banks (and for leasing companies in Chile) since June 1990. After the first two auctions, Chile began to hold separate auctions for banks and leasing companies. The Central Bank is the auctioneer in Bolivia, and the Development Bank of Chile, a government institution, 
in Chile. Participants are free to set interest rates for final users. Multiple products involving several maturities, different currencies, and fixed and variable interest rates have been auctioned simultaneously in both countries.

Floor prices have been linked to an average of existing short-term rates. Participants submit sealed bids stating the product and quantity desired and the interest rate offered. Discriminatory price rules are followed. Both countries enjoin the use of funds for working capital, the purchase of imported capital goods or previously financed goods, housing, urban development, or for any form of transportation intended for personal use. Chile has no sectoral restrictions on the use of the funds, but Bolivia has some a as result of previous loan covenants. In both countries, the auctioneer analyzes the bids, compares bids across products, selects cut-off rates for each product, and then allocates funds from highest to lowest interest rates until the funds are exhausted or there are no more bids above the cut-off levels.

Between June 1990 and January 1992, Bolivia and Chile together held more than 30 auctions. Except for the first few auctions in Bolivia, in which collusion was suspected, the auctions have been, by and large, problem-free. Since Bolivia ceased its practice of informing bidders of floor prices, the quantity to be auctioned, and the auction results, performance has improved.

Overall, the results have been quite promising. The auctions have removed virtually every element of personal discretion evident in conventional credit allocation methods, making the allocation of credit fully transparent. Wasteful rent-seeking opportunities have been eliminated, and the two governments have increased their share of the rents. Participation has been high, the bidding competitive. Allowing leasing companies to participate has significantly strengthened competitiveness in Chile. Leasing companies have been more active than banks in terms of number of participants and quantity of funds demanded and awarded. The auctions have elicited prices that compare favorably with the costs of capital to financial intermediaries from alternative sources (shorter term) and have established competitive price benchmarks for the first time for some forms of long-term credit. There seems to be no evidence of collusion or adverse selection, potentially the most damaging problems in auctions, and repayments rates, so far, have been near perfect.

Some fine-tuning is still needed in such areas as criteria for comparing bids across heterogeneous products, the selection of floor prices for different products, and the number of bids allowed per participant and product. All things considered, however, the auctioning of development credit has been a clear and significant improvement over previous methods of allocating credit.

\section{Recommendations}

To summarize, auctions ought to be considered when current mechanisms do not allocate credit fairly and efficiently, when there is no proxy reference 
rate for long-term credit, when there is evidence of competition or potential competition in the banking sector, when private banks play a strong role, and when competent supervisory agencies can assess the credit risks of potential participants.

Several recommendations also follow from the analysis of design issues for development credit auctions.

- Eligibility. Private banks and appropriately screened (adequately capitalized and managed) nonbank financial institutions such as leasing companies should be eligible to participate. Government-owned banks satisfying all eligibility requirements should not be permitted to bid but may be permitted to obtain funds at the average auction rates. Screening for creditworthiness should be conducted by external supervisory and securities rating agencies, which may need to be established for that purpose. A nonrefundable application fee is also recommended as a self-screening device to increase efficiency. In some environments, constraints should be imposed on amounts that specific types of institutions can borrow.

- Type of product. Specific conditions in each country should determine whether credit or credit lines are auctioned. The goal should be maximum flexibility in the use of the funds, so there should be no sectoral constraints on credit use. Auctioning should begin with a single product. Selection of the product should be responsive to the preferences of participants.

- Objective. The objective of development credit auctions should be to maximize expected returns, taking default risk into account.

- Type of auction. Sealed-bid, discriminatory price auctions with multiple bidding should be considered, since they are less vulnerable to collusive behavior than other types of auction mechanisms. Auctions should be held at regular intervals to reduce the amount of funds awarded at each auction. Where private banks are few and creditworthy nonbank financial institutions have an established presence, priority-level auctions may be a desirable alternative for inducing competition between groups with different alternative costs of funds or risk classifications. Assigned priority levels are used to favor bids from lower-valuation groups relative to those from higher-valuation groups.

- Adverse selection and moral hazard. Setting eligibility criteria and caps on the maximum cumulative amount of credit an institution can purchase at auctions will help to diminish the risks of adverse selection (the tendency to attract the highest-risk participants), and moral hazard (the tendency to lend for riskier projects or investments at higher interest rates), thereby increasing the probability of default. The caps can be reassessed in light of the performance of the institution. Covenants can also be established to govern the use of funds.

- Collusion. Several steps can be taken to make collusion and other fraudulent behavior more difficult. Most important is setting a floor price and 
revising it periodically to reflect changes in interest rate levels and bidding patterns. The floor price should be linked to the opportunity cost of capital to participants and should not be lower than the government's marginal cost of borrowing. Neither the floor price nor the amount of funds to be awarded at each auction should be revealed. If cheating or collusion is suspected, specific information on the winning bids should also be withheld; experimenting with increases in the floor price should also help to root out collusive behavior. Encouraging the participation of many different types of qualified financial institutions will also stifle collusive activity, and handicapping bids across groups should be considered under certain circumstances.

Not all countries that lack a market in long-term credit need to introduce credit auctions. The need may be far less pressing in countries with a welldeveloped market in government securities that includes some instruments with terms substantially longer than one year. Rates on those securities can be used as benchmarks for pricing development credit. Mexico has taken this approach. More broadly, auctions ought to be viewed as part of a package of reforms to foster the development of financial markets. The auctioning of longterm credit can serve as a transition mechanism to complement other reforms that facilitate the development of long-term credit and securities markets.

In sum, development credit auctions ought to be viewed as but one of several mechanisms to improve the efficiency of development credit pricing and allocation. When current practices are clearly unsatisfactory, properly designed auctions are likely to do much better. Compared with conventional methods, the chief problems that are potentially worse with credit auctions-and so need to be guarded against-are collusion and adverse selection. Auctions can be designed to overcome these problems, however. Instituting an auction also brings credibility to a government's commitment to change. It marks a radical break with the past, institutionalizes the new rules, and increases the system's transparency and fairness by taking decisions about credit allocation out of the hands of individuals. The success of auctions in Bolivia and Chile, countries with large differences in their financial markets and their economies, validates in practice the theoretical arguments for auctions as a mechanism for allocating credit.

\section{Appendix. How Various Types of Credit Auctions Compare in Generating Revenue}

This appendix presents the results from the literature on how various types of credit auctions compare in revenue-generating properties (for details, see Milgrom 1989; Bulow and Roberts 1989; Milgrom and Weber 1982, 1989; Weber 1983; McAfee and McMillan 1987; and U.S. Treasury 1992). 
ORAL OR OPEN VERSUS SEALED-BID AUCTIONS. The open or English auction yields higher expected returns than the sealed-bid, uniform price auction, which in turn yields higher expected returns than the sealed-bid, discriminatory price auction. Moreover, if bidders' beliefs are correlated or statistically dependent-as is the case for credit auctions - particularly if bidders are uncertain about their valuations (as with credit lines), expected revenue for the seller is higher under an open or English auction than under a sealed-bid auction. The reason: when bidders are uncertain about their valuations, they can acquire valuable information by analyzing and incorporating into their decisionmaking the bidding behavior of their competitors during the course of an open auction. That opportunity is denied under sealed-bid auctions. The result: more aggressive bidding and higher expected rates under English auctions.

Simultaneous Versus SEQUeNTIAL AUCTIONS. Sequential first-price and second-price auctions generally yield greater expected revenues than their simultaneous counterparts, the discriminatory price and uniform price auctions. The reason: in sequential auctions bidders are forced at each round to disclose some information to the other bidders. The result: because auctions that provide quality information (information affecting bidders' valuations and known to be known by the auctioneer) to bidders before the event generally benefit the seller (because bidders assume the worst when no information is provided), sequential auctions tend to generate more revenue for the sellers than do simultaneous auctions. Thus, with multiple objects like credit, first- and secondprice sequential auctions generate greater expected revenue than their simultaneous counterparts (Milgrom and Weber 1989). ${ }^{12}$

UNIFORM VERSUS DISCRIMINATORY PRICING. Because of the interdependence of valuations in credit auctions (affiliated valuations), English auctions yield higher expected revenue than uniform price auctions, which yield higher expected revenue than sealed-bid, discriminatory price auctions. The reason: under discriminatory price auctions, bidders pay what they bid, whereas in an English or uniform price auction, bidders' payments depend not only on their own bids but also on their private valuation, which affects the bids of others (affiliated valuation). That extra effect tends to increase the slope of the marginal profit of the bidder under an English or uniform auction, an effect not found in sealed-bid, discriminatory price auctions.

Generally, the revenue results for English auctions and uniform second-price auctions are equivalent when bidders are certain about their value estimates, as would be the case with credit auctions. When bidders are uncertain about their estimates, as might be the case for credit line auctions, English auctions tend to induce higher rates. The reason: when bidders are uncertain, they acquire useful information by analyzing others' bids during the auction. Because that cannot occur in a uniform price auction with its sealed bids, bidding tends to be more aggressive under English auctions. 
The results discussed thus far for various types of auctions assume risk-neutral bidders. With risk-averse bidders, however, there is no unambiguous ranking among types of auctions in an affiliated valuations environment. ${ }^{13}$

EFFICIENCY. Because they elicit true valuations, English, second-price, and uniform price auctions tend generally to result in efficient allocations, with credit allocated to bidders with the highest valuations. Under first-price or discriminatory price bidding, shading a bid below one's reservation price decreases both the probability of winning and the price to be paid. Under second-price or uniform price bidding, shading a bid below one's reservation price decreases the probability of winning but not the price to be paid. It is that asymmetry that induces efficiency and makes second-price and uniform price auctions superior to first-price and discriminatory price auctions. With credit auctions, however, special care is needed in defining efficiency, because higher valuations need not mean higher expected returns. Also second-price and uniform price auctions are efficient because the process for devising bidding strategies is very simple: because the optimal bid is the true valuation, complex calculations are not required. By contrast, coming up with optimal bids in discriminatory price auctions requires elaborate computations since optimal bids do not correspond to true valuations.

PRIORITY-LEVEL AUCTIONS. What little work has been done on priority-level auctions suggests that they yield higher expected revenue than any of the standard auctions, oral or sealed bid (see, for example, McAfee and McMillan 1989). However, those results were obtained for fairly restrictive settings and single objects. Nevertheless, priority-level auctions are worth exploring since they expand the pool of bidders by normalizing differences among types of bidders with different alternative costs of funds or risk classifications. Such auctions boost expected revenue and make collusive agreements more difficult by increasing the number of bidders (Harris and Raviv 1981).

Chile's experience is instructive. The most eager participants in credit auctions have been leasing companies, which have higher costs of raising funds than mainstream banking or financial institutions, mainly because they cannot offer deposit accounts or use rediscount facilities (Guasch and Glaessner 1992). That raises their reservation interest rates above those of commercial banks. Because the rates reflect opportunity costs and the differences arise from the institutional environment and regulations, priority-level price auctions are an appealing option for reducing the edge leasing companies have and increasing competition.

What about extending the argument to individual bidders as well as institutions, since there is wide variation in risks within each group? That variation means that two identical bids could have two very different expected rates of return, so some consideration should be given to assessing significant differences in risk within groups and handicapping them appropriately. 


\section{Notes}

J. Luis Guasch is a principal economist in the Latin America and the Caribbean Regional Office at the World Bank and a professor of economics at the University of California, San Diego. Thomas Glaessner is a senior financial economist in the Latin America and the Caribbean Regional Office at the World Bank. The authors thank Charles Blitzer, Jeremy Bulow, Luis Bustos, Mark Dorfman, Heywood Fleisig, Juan Foxley, Edward Green, Feliciano Iglesias, Ezequel Machado, Robert Marshall, Ignacio Mas, John McMillan, John Page, John Parsons, Sarath Rajapatirana, S. Ramachandran, Edilberto Segura, Marcelo Selowsky, Bill Shaw, and Joel Sobel for helpful comments and discussions. For an extensive analysis of the issues discussed in the article and of the experience in Chile and Bolivia, see Guasch and Glaessner (1992).

1. These auction prices are not market prices, however. The absence of a market for longterm credit before the auctions indicates that lenders and borrowers could not agree on a market price- and so there was no market. Either the reservation price of borrowers was lower than that of lenders or the incentive effects induced by the high rates at which lenders were willing to lend made the rates unprofitable (relative to alternative terms), so that lenders preferred to ration long-term credit. Auctions create the market by committing the government to accept the rates offered by the borrowers. What auctions can discover, at best, therefore, is the reservation price of the borrowers. Thus auction rates are not market rates, and they imply a subsidy element equal to the difference between the auction rate and the minimum rate necessary to induce lenders to supply long-term credit.

2. An example is Mexico's auctioning of housing mortgage-finance funds. The interest rate to final users is administratively set below market rates. The high bids submitted by developers in periods of excess demand illustrate the point that the auction mechanism allows the government to capture some of the rents that otherwise would have been captured by the financial intermediaries.

3. For U.S. Treasury bills and bonds, coupon rates are set before the auction, and bidders submit their bids as total amounts they would pay in exchange for a bundle of bonds. This total dollar price implies an effective yield, like an interest rate, and is an example of implicit interest rate bidding. Recently the U.S. Treasury has begun to use a uniform price auction instead of the discriminatory price auction previously used, to reduce the possibility of a single bidder cornering the market and extracting rents in the secondary T-bill market (U.S. Treasury 1992).

4. These horticulture auctions resemble credit auctions in some ways. There is a large number of bidders who are interested in purchasing some amount of a homogeneous commodity. Like credit, fruits and vegetables can be easily exchanged among colluding bidders at the auction site-a sharing of collusive gains. To reduce the opportunities for collusion, auctioneers limit the lot sizes that can be purchased at one time and use randomized reserve strategies. A representative of the auction house roams the floor to look for obvious signs of bidder collusion, such as excessive communication between bidders during the auction. A warning is issued to such bidders, who may even be ejected from the auction.

5. Manipulation by the seller also needs to be considered. For example, in second-price or uniform price auctions, the auctioneer can gain by introducing a spurious bid that is very close to the highest bid (in a second-price auction) or to the lowest awarded bid (in a uniform price auction).

6. If collusion is feared, there is a simple reason why sealed-bid auctions are preferable to English auctions. Suppose the cartel maintains cohesiveness by threatening retaliation against defectors. With a sealed-bid auction, retaliation must wait until the next auction, because defection becomes evident only after the bidding is over. With an English auction, retaliation can come in the current auction, and the immediacy of the threat means that the collusion is more likely to succeed.

7. Hansen's (1988) results suggest that first-price auctions lead to more efficient allocations when purchase quantities are endogenous (a relevant consideration in credit auctions). This refers to settings where agents compete through price-bidding for the right to sell a quantity of product that depends on the best price bid. And in studies of results for the auctioning of con- 
tracts for harvesting timber using both types of auctions, Hansen (1986) also found that the differences in revenue were statistically insignificant.

8. A relevant example is government procurement contracts. Governments often favor domestic suppliers over foreign ones. For instance, under buy-American legislation, the U.S. government offers a 6 percent price preference to domestic suppliers. That is, as long as the lowest price submitted by a domestic supplier does not exceed the lowest price submitted by a foreign supplier by more than 6 percent, the contract goes to the domestic supplier.

9. Although some people argue that repeated auctions make collusion easier to sustain because repetition allows for the possibility of retaliation in the event of defection, we would counter that, easier retaliation notwithstanding, coordinating bids over several auctions has significant problems when participants are heterogeneous and there are no side payments.

10. This argument assumes no manipulation of the amount of funds to be auctioned by the auctioneer because the amounts are determined by a committee in the Apex agency. Several key agencies are represented in that committee.

11. A word of caution: although the outcome may appear to demonstrate collusive behavior, widespread bidding of the floor price can demonstrate competitive behavior, reflecting unanimity in the unilateral valuations. Bidding the floor price is also the optimal noncollusive strategy when bidders believe that there will be an excess supply of funds awarded at rates at least equal to the floor price, which appears to be the case in Bolivia. If bidders believe that the amount of funds being auctioned is large enough, there is no point in bidding above the floor price.

12. The results were derived for a general environment characterized by symmetry, risk-neutrality, and fewer items than bidders.

13. This is not the case in an independent private valuation environment-which does not apply here - where discriminatory price sealed-bid auctions generate higher expected revenue than English or uniform price auctions.

\section{References}

The word "processed" describes informally reproduced works that may not be commonly available through library systems.

Bulow, Jeremy, and John Roberts. 1989. "The Simple Economics of Optimal Auctions." Journal of Political Economy 97 (October): 1060-90.

Graham, Daniel, and Robert Marshall. 1987. "Collusive Bidder Behavior at Single-Object Second-Price and English Auctions." Journal of Political Economy 95 (December): 1217-39.

Graham, Daniel, Robert Marshall, and Jean-François Richard. 1990. "Differential Payments within a Bidder Coalition and the Shapley Value." American Economic Review 80 (June): 493-510.

Guasch, J. Luis, and Thomas Glaessner. 1992. "Auctioning Credit." 3 vols. Regional Study 15. World Bank, Latin America and Caribbean Region, Technical Department, Washington, D.C. Processed.

Hansen, R. G. 1985. "Empirical Testing of Auction Theory." American Economic Review 75 (May): 156-59.

1986. "Sealed-Bid versus Open Auctions: The Evidence." Economic Inquiry 24 (January): $125-42$.

- 1988. "Auctions with Endogenous Quantities." Rand Journal of Economics 19 (Spring): $44-58$.

Harris, Milton, and Artur Raviv. 1981. "Allocation Mechanisms and the Design of Auctions." Econometrica 49 (November): 1477-1500.

Hendricks, Kenneth, and Robert H. Porter. 1988. "An Empirical Study of an Auction with Asymmetric Information." American Economic Review 78 (December): 865-83. 
Hendricks, Kenneth, Robert H. Porter, and B. Boudreau. 1987. "Information, Returns, and Bidding Behavior in OCS Auctions: 1954-1969." Journal of Industrial Economics 35 (June): $517-42$.

McAfee, R. Preston, and John McMillan. 1987. "Auctions and Bidding." Journal of Economic Literature 25 (June): 699-738.

- 1989. "Government Procurement and International Trade." Journal of International Economics 26: 291-308.

Milgrom, Paul R. 1989. “Auctions and Bidding: A Primer.” Journal of Economic Perspectives 3 (Summer): 3-22.

Milgrom, Paul R., and Robert J. Weber. 1982. "A Theory of Auctions and Competitive Bidding." Econometrica 50 (November): 1089-122.

. 1989. "A Theory of Auctions and Competitive Bidding II." Yale University, New Haven, Conn. Processed.

Plott, Charles R. 1982. "Industrial Organization Theory and Experimental Economics." Journal of Economic Literature 20 (December): 1485-527.

Smith, Vernon L. 1982. "Microeconomic Systems as Experimental Science." American Economic Review 72 (December): 923-55.

U.S. Treasury. 1992. Joint Report on the Government Securities Market. Washington, D.C.: U.S. Government Printing Office. January.

Weber, Robert J. 1983. “Multiple-Object Auctions.” In Richard Engelbrecht-Wiggans, Martin Shubik, and Robert M. Stark, eds. Auctions, Bidding, and Contracting: Uses and Theory. New York: New York University Press. 